\title{
EXPERIMENTAL STUDY ON THE PERFORMANCE OF A MECHANICAL COOLING TOWER FITTED WITH DIFFERENT TYPES OF WATER DISTRIBUTION SYSTEMS AND DRIFT ELIMINATORS
}

\author{
M. Lucas *, J. Ruiz, P. J. Martínez \\ Departamento Ingeniería de Sistemas Industriales \\ Universidad Miguel Hernández \\ Avda. de la Universidad, s/n, 03202 Elche, Spain \\ Telephone: +34966 658887 Fax: +34 966658979 \\ Email: mlucas@umh.es
}

\author{
A.S. Kaiser, A. Viedma, B. Zamora \\ Departamento de Ingeniería Térmica y de Fluidos \\ Universidad Politécnica de Cartagena (Campus Muralla del Mar) \\ Dr. Fleming, s/n, 30202 Cartagena, Spain
}




\section{Nomenclature}

$A_{V} \quad$ surface area of water droplets per unit volume of tower, $\left(\mathrm{m}^{2} / \mathrm{m}^{3}\right)$

c constant for the ASHRAE correlation

$\mathrm{C}_{\mathrm{pw}} \quad$ specific heat at constant pressure of water, $\left(\mathrm{kJ} / \mathrm{kg}_{\mathrm{w}} \mathrm{K}\right)$

G mass flow rate of dry air, $\left(\mathrm{kg}_{\mathrm{a}} / \mathrm{s}\right)$

$\mathrm{h} \quad$ enthalpy of moist air, $\left(\mathrm{kJ} / \mathrm{kg}_{\mathrm{a}}\right)$

$h_{D} \quad$ convective mass transfer coefficient, $\left(\mathrm{kg}_{\mathrm{a}} / \mathrm{m}^{2} \mathrm{~s}\right)$

$\mathrm{h}_{\mathrm{s}, \mathrm{w}} \quad$ specific enthalpy of saturated water vapor at $\mathrm{t}_{\mathrm{w}},\left(\mathrm{kJ} / \mathrm{kg}_{\mathrm{w}}\right)$

L mass flow rate of water, $\left(\mathrm{kg}_{\mathrm{w}} / \mathrm{s}\right)$

GWDS gravity water distribution system

m constant for the ASHRAE correlation

$\mathrm{m}_{\mathrm{a}} \quad$ mass flow rate of dry air, $\left(\mathrm{kg}_{\mathrm{a}} / \mathrm{s}\right)$

$\mathrm{m}_{\mathrm{w}} \quad$ mass flow rate of water, $\left(\mathrm{kg}_{\mathrm{w}} / \mathrm{s}\right)$

n constant for the ASHRAE correlation

NTU number of transfer units

PWDS pressure water distribution system

t dry bulb temperature of moist air, $\left({ }^{\circ} \mathrm{C}\right)$

$\mathrm{t}_{\mathrm{w}} \quad$ water temperature, $\left({ }^{\circ} \mathrm{C}\right)$

TC tower characteristic

V volume of tower, $\left(\mathrm{m}^{3}\right)$

Subscripts

a moist air

w water

1 inlet

2 outlet 


\begin{abstract}
Cooling towers are evaporative heat transfer devices in which atmospheric air cools warm water, with direct contact between the water and the air by evaporating part of the water. The principle of operation of cooling towers requires spraying or distributing water over a heat transfer surface (packing) across or through which a stream of air is passing. As a result, water droplets are incorporated in the air stream and, depending on the velocity of the air, will be taken away from the unit. This is known as drift. Although cooling tower drift is objectionable for several reasons, the most hazardous problem concerning human health is the emission of chemicals or microorganisms into the atmosphere. Undoubtedly, regarding microorganisms, the most well-known pathogens are the multiple species of bacteria collectively known as legionella.

The binomial water distribution system-drift eliminator is identified to be that mainly responsible for cooling tower drift. While water distribution systems affect the mechanics of setting up the drops, drift eliminators work by changing the direction of the airflow and separating droplets from the airstream through inertial impact.

The drift eliminator's performance can be quantified mainly by two factors: droplet collection efficiency and the pressure drop across the eliminator. In contrast, water distribution systems are characterized by the pressure drop across itself and the achieved size of the particle spread. Alongside drift, the binomial water distribution system-drift eliminator affects the cooling tower performance.

From the reviewed bibliography, some studies assessing the effect of the drift eliminator on cooling tower performance have been found. Nevertheless, no studies regarding the influence of the water distribution system on the cooling tower's performance have been detected. In this sense, this paper studies the thermal performance of a forced draft counter-flow wet cooling tower fitted with two water distribution systems (the pressure water distribution system (PWDS) and gravity water distribution system (GWDS)) for six drift eliminators for a wide range of air and water mass flow rates. The data registered in the experimental set-up were employed to obtain correlations of the tower characteristic, which defines the cooling tower's thermal performance. The outlet water temperature predicted by these correlations was compared with the experimentally registered values, obtaining a maximum averaged difference of
\end{abstract}

$\pm 0.95 \%$.

\title{
Keywords
}

Cooling tower, drift, drift eliminator, water distribution system 


\section{Introduction}

Cooling towers are evaporative heat transfer devices in which atmospheric air cools warm water, with direct contact between the water and the air by evaporating part of the water. Chilled water falls into the tower basin while the removed heat leaves the device as warm air. They are commonly used to dissipate heat from power plants, water-cooled refrigeration, air conditioning and industrial processes. The principle of operation of cooling towers requires spraying or distributing water over a heat transfer surface (packing) across or through which a stream of air is passing. As a result, water droplets are incorporated in the air stream and, depending on the velocity of the air, will be taken away from the unit. This is known as drift and it is independent of water lost by evaporation.

Although cooling tower drift is objectionable for several reasons (Lewis, [1]) such as ensuing corrosion problems on equipment, piping and structural steel, accumulated salts on downwind vegetation or ice formation during winter months (Pedersen [2]), undoubtedly the most hazardous problem concerning human health is the emission of chemicals or microorganisms to the atmosphere. Regarding microorganisms, the most well-known pathogens are the multiple species of bacteria collectively known as legionella. These bacteria tend to thrive at the range of water temperatures frequently found in these cooling systems. Hence, workers or other people near a cooling tower may be exposed to drift, may inhale aerosols containing the legionella bacteria, and may become infected. Numerous legionella outbreaks have been linked to cooling towers (Bentham and Broadbent [3] and Isozumi et al. [4]). In order to minimize cooling tower drift, baffles known as drift eliminators, which work by changing the direction of the airflow as it passes through them, are located at the cooling tower exit surface. As a result, droplets are collected by inertial impact.

The drift eliminator's performance can be quantified mainly by two factors: On the one hand, the droplet collection efficiency and, on the other, the pressure drop across the eliminator. Chan and Golay [5] developed a numerical technique to design a drift eliminator for a particular cooling tower by setting a pressure drop limit, and then choosing the geometry that provides the best collection efficiency. For the purpose of spreading warm water, which needs to be cooled within the cooling tower packing, a component identified as a water distribution system is set in cooling towers. Mohiuddin and Kant [6], made a specific classification of water distribution systems where two different types of water distribution systems can be found in general use. On the one hand, splash systems break up the water into small particles in order to expose as much water surface as possible to the air. On the other hand, film flow systems distribute the liquid as a thin film (without the formation of droplets) on the packing located underneath.

In order to quantify the water distribution systems, two factors might be taken into account. On the one hand, the pressure drop across the system and, on the other, the size of the droplets achieved. The higher the pressure drop across the water distribution system is, the smaller the size of water droplets spreading over the packing, and therefore more pumping work is required. Meanwhile, the size of the droplets achieved by the system will affect the cooling tower performance and cooling tower drift. Drift eliminator collection efficiency will decrease for the smaller droplets, and consequently cooling tower drift will increase (Zamora and Kaiser [7]). At the same time, the hypothesis to be tested in this study is that a relationship exists between the cooling tower capacity and the water distribution system fitted. 
In order to evaluate the cooling tower's thermal performance, a dimensionless parameter is defined. The accepted concept of cooling tower performance is the tower characteristic (TC onwards), usually determined by the water-to-air mass flow ratios (L/G). Many studies assessing the influence of cooling tower constructive elements can be found in the literature. Regarding the packing, Thomas and Houston [8] and Lowe and Christie [9] developed heat and mass transfer correlations with air and water mass flow rates as independent variables by using cooling towers fitted with different types of packing. Kelly and Swenson [10] studied the heat transfer and pressure drop characteristics of a splash grid type of cooling tower packing. These authors correlated the TC with the water-to-air mass flow ratio and concluded that the factors affecting the TC value were found to be the water-to-air ratio, the packed height, the deck geometry and, to a very small extent, the inlet water temperature. Goshayshi and Missenden [11] experimentally studied the mass transfer and the pressure drop characteristics of smooth and rough surface corrugated packing in atmospheric cooling towers.

Several authors developed heat and mass transfer correlations in terms of the water-to-air mass flow ratio, like Bedekar et al. [12] for a counter-flow packed bed mechanical cooling tower with a film type packing, Milosavljevic and Heikkila [13] for two pilot-scale cooling towers with seven types of counter-flow film type packings, Gharagheizi et al. [14] for two film-type packings, and Lemouari et al. [15] for a forced draft counter-flow wet cooling tower with a vertical grid-type packing. Elsarrag [16] developed an experimental study to evaluate the heat and mass transfer coefficients of an induced draft ceramic tile packing cooling tower. The mass transfer coefficient obtained from the dimensional analysis is correlated with the water-to-air mass flow ratio and a dimensionless group which measures the degree of difficulty of the mass transfer.

Besides the packing, drift eliminators affect the cooling tower's performance as well. Hajidavalloo et al. [17], in their work of cross flow cooling towers in variable wet bulb temperature, include a brief discussion about the effect of the drift eliminator on tower performance, taking only a reduction of air flow rate into account. Lucas et al. [18] developed an experimental study on the effect of installing different drift eliminators on the thermal performance of a mechanical cooling tower. The authors concluded that the drift eliminator became an additional packing volume and contributed to the heat and mass transfer exchange because of the wetting of themselves. They also correlated TC with water-to-air mass flow ratios for the six drift eliminators tested. As all the tests were carried out using a pressure water distribution system (splash system), the group of researchers questioned what variations in the cooling tower's performance would introduce another water distribution system, aiming to minimize the cooling tower drift. In this sense, the main objective of this work is to experimentally investigate the thermal performance of a forced draft counter-flow cooling tower (FDCT) with two water distribution systems and six different drift eliminators (the ones tested in Lucas et al. [18]) in order to assess the influence of the distribution system on the cooling tower thermal performance. An additional objective is to analyze the interaction between distribution systems and drift eliminators. 


\section{Cooling tower theory}

The information described in this section has its origin in the work of Mohiuddin and Kant [6], which has been taken as a reference. Considering a counter-flow cooling tower with negligible resistance to mass transfer at the water-air interface, no difference between bulk water and the interface, no evaporation and assuming that the flow pattern is vertical with the water and air falling downwards and upwards through the tower, respectively, we can solve the flow as a one-dimensional problem.

Each water particle is surrounded by a film of saturated air at the bulk water temperature (Figure 1). The air is heated and it becomes saturated as it passes through the tower. The heat is transferred from the water to the air partly as sensible heat and partly as latent heat. The two processes were combined by Merkel [19] into a single equation:

$$
m_{w} \cdot C_{p w} \cdot d t_{w}=h_{D} \cdot A_{v} \cdot d V \cdot\left(h_{s, w}-h\right)=m_{a} \cdot d h
$$

Which upon integration yields:

$$
\begin{gathered}
\frac{h_{D} \cdot A_{v} \cdot V}{m_{w}}=C_{p w} \int_{t_{w, 1}}^{t_{w, 2}} \frac{d t_{w}}{\left(h_{s, w}-h\right)} \\
\frac{h_{D} \cdot A_{v} \cdot V}{m_{a}}=\int_{h_{1}}^{h_{2}} \frac{d h}{\left(h_{s, w}-h\right)}
\end{gathered}
$$

Despite the right-hand side of equations (2) and (3) containing only the thermodynamic quantities for the cooling process and depending on the initial and end conditions of the air present in the tower, the lefthand side is independent of these and is determined by the characteristics of the tower design, $h_{D}, A_{V}$ and $\mathrm{V}$, and the flow rates of water and air, respectively.

The ( $h_{D} A_{V} V / m_{w}$ ) ratio is also known as KaV/L or tower characteristic (as previously mentioned), which is the accepted concept of the cooling tower's performance whereas $\left(h_{D} A_{V} V / m_{a}\right)$ or $K a V / G$ is referred as number transfer units (NTU).

$$
\begin{gathered}
T C=\frac{h_{D} \cdot A_{V} \cdot V}{m_{w}}=C_{p w} \int_{t_{w, 1}}^{t_{w, 2}} \frac{d t_{w}}{\left(h_{s, w}-h\right)} \\
N T U=\frac{h_{D} \cdot A_{V} \cdot V}{m_{a}}=\int_{h_{1}}^{h_{2}} \frac{d h}{\left(h_{s, w}-h\right)} \\
T C=\frac{m_{a}}{m_{w}} \cdot N T U
\end{gathered}
$$

As the integral shown in Equation (2) cannot be solved directly, an integration method might be used for TC calculation. Many methods such as the Merkel method, Berman method or NTU numerical method, among others, aim to solve this problem, but as suggested by Mohiuddin and Kant [6] and CTI [20], the Tchebyshev integration method provides better results. According to this method, for the integral written in equation (2), one can write 


$$
C_{p w} \int_{t_{w, 1}}^{t_{w, 2}} \frac{d t_{w, w}}{\left(h_{s, w}-h\right)}=C_{p w} \frac{t_{w, 2}-t_{w, 1}}{4} \sum_{j=1}^{4} \frac{1}{\left(h_{s, w}-h\right)_{j}}
$$

Therefore

$$
T C=C_{p w} \frac{t_{w, 2}-t_{w, 1}}{4} \sum_{j=1}^{4} \frac{1}{\left(h_{s, w}-h\right)_{j}}
$$

The procedure to calculate the cooling tower performance following Tchebyshev's method is described step by step in Table 1 . 


\section{Experimental apparatus and procedure}

The installation where the experiments were carried out is located on the roof of one of the laboratories at the Miguel Hernandez University (Elche, Spain). The forced draft cooling tower has a cross-sectional area of $0.70 \times 0.48 \mathrm{~m}^{2}$, a packing section $1.13 \mathrm{~m}$ high and a total height of $2.597 \mathrm{~m}$. The packing material consists of fiberglass vertical corrugated plates. While the airflow rate is circulated counter-flow by an axial fan and is maintained at different levels by a frequency switcher, the water mass flow rate can be changed manually by means of a balancing valve. The thermal load consists of an electrical heater of 30 $\mathrm{kW}$ placed in a water tank. A schematic arrangement of the facility can be seen in Figure 2.

The thermal performance of the cooling tower was experimentally investigated for two water distribution systems (Figure 3) and six different drift eliminators. The cooling tower capacity was also calculated when no drift eliminator was fitted. On the one hand, the pressure water distribution system (PWDS onwards) is equipped with pressure nozzles, which are used to distribute the water droplets uniformly over the packing. On the other hand, the gravity water distribution system (GWDS onwards) consists of a large channel, which covers the effective part of the cooling system outlet section and operates under gravity. Drift eliminators are now described. Drift eliminators A, B and C, present a zigzag structure and consist of fiberglass plates separated at distances of 55, 37 and $30 \mathrm{~mm}$, respectively. Drift eliminator $\mathrm{D}$ is made of plastic as a honeycomb, while drift eliminator $\mathrm{E}$ is a $45^{\circ}$ tilted rhomboid mesh also made of plastic. Drift eliminator F has the same structure as eliminator E with a $45^{\circ}$ tilted lower half and a $135^{\circ}$ tilted upper half. The drift eliminators are shown in Figure 4.

The information measured during the experiments by the sensor devices, whose specifications are shown in Table 2, was monitored with an Agilent 34970A Data Acquisition/Data Logger Switch Unit. Concerning the experimental procedure, nine sets of experiments for each combination of water distribution system-drift eliminator were performed, for a total of 126 tests. Three air flow rates (25, 37.5 and $50 \mathrm{~Hz}$ ) and three water flow rates $(0.72,1.083$ and $1.44 \mathrm{l} / \mathrm{s})$ were fixed with the aim of obtaining different water-to-air mass flow ratios. The operational range of water-to-air mass flow ratios for this work is about $0.5-2$.

In order to obtain the TC for the experiments carried out, "Thermal performance acceptance testing of mechanical draught series wet cooling towers”, UNE 13741, was accepted as a reference for stationary conditions. It describes the procedure for a test to be valid by marking the limits on the variation in test conditions. In this way, variations of the circulating water flow rate, heat load and range shall not be greater than $5 \%$ while wet-bulb temperature and dry-bulb temperature linear least square trends shall not exceed $1^{\circ} \mathrm{C}$ and $3^{\circ}$ per hour, respectively. The maximum deviation of the wet-bulb temperature may not exceed its average value during the test period $\left( \pm 1.5^{\circ} \mathrm{C}\right)$. The same is valid for the dry-bulb temperature with a deviation of $\pm 4.5^{\circ} \mathrm{C}$. The wind velocity shall not exceed $7 \mathrm{~m} / \mathrm{s}$ for one minute and its average value during the test period shall not exceed $4.5 \mathrm{~m} / \mathrm{s}$. The duration of the test run shall not be less than one hour. 


\section{Results and discussion}

Figure 5 shows the experimental variation of the TC with the water-to-air mass flow ratio for the tower fitted with the drift eliminators tested and the GWDS. The experimental uncertainty, calculated according to ISO Guide [21] (with a level of confidence of 95\%), using sensor specifications shown in Table 2, showed a maximum and an average value of $14.4 \%$ and $6.6 \%$, respectively, for the water-to-air mass flow ratio and values of $3.7 \%$ and $3.3 \%$ for the TC. As can be seen, the tower characteristic decreases while the water-to-air mass flow ratio increases for every drift eliminator. It can also be appreciated that for the same value of water-to-air mass flow ratio, the TC magnitude is different for the drift eliminators tested. This fact corroborates the conclusions reached by Lucas et al. [18], who assessed the drift eliminator's influence on heat and mass transfer processes taken place in the cooling tower.

Figure 6 depicts the correlations obtained for the drift eliminators tested and the GWDS. When comparing PWDS and GWDS results, it can be observed that for each drift eliminator tested, the cooling tower capacity is higher when the PWDS is equipped. The explanation given to this phenomenon is related to the small droplet size achieved with the PWDS because of the breaking up of the water into small particles. As the size of the obtained droplets by the water distribution system is smaller, the heat and mass exchange area per unit of volume ( $\mathrm{A}_{\mathrm{V}}$ coefficient, equation (4)) increases.

Figure 7 shows the comparison between the tested drift eliminators when gravity and pressure water distribution systems are respectively equipped, and, as discussed earlier, the higher cooling capacity for the PWDS tests can be assessed.

For the purpose of comparing the cooling tower performance between the distribution systems, Table 3 depicts the difference, averaged and maximum, in terms of correlated TC, between the eliminators tested with GWDS and PWDS. The averaged difference was obtained by evaluating the TC for each water-toair mass flow ratio value tested and averaging those results while the maximum difference was calculated for the value of water-to-air mass flow ratio where the cooling tower performance difference between eliminators reached the greatest variation. 
The cooling tower thermal behavior modification with the installation of different drift eliminators can be explained by two physical phenomena, one attributed to the increasing of the term $A_{V}$, and the other because of the variation of the $h_{D}$ coefficient, both presented in equation (4). The $A_{V}$ term is referred to the surface area of heat and mass exchange per unit volume of tower, while $h_{D}$ stands for the convective mass transfer coefficient. As eliminators get wet because of cooling tower drift, the eliminator itself becomes an additional surface of heat and mass transfer. Meanwhile, the flow pattern enforced by the drift eliminator affects the velocity distribution inside the tower and therefore the convective mass transfer coefficient (which depends mostly on the air velocity).

Attending to the less altered flow pattern introduced by an eliminator, the sequence would be the one begun with no drift eliminator, drift eliminators $\mathrm{F}$ and $\mathrm{E}$ (the first does not perturb the flow, and $\mathrm{E}$ and $\mathrm{F}$, made of wire mesh, do not affect as much as the others because they are less intrusive) followed by drift eliminator D (due its 3D shape) and ended by drift eliminators A, B and C because their asymmetric shape and the increasing number of laths.

Therefore, the order of eliminators arranged from the fewest to the most altered flow pattern introduced is No Eliminator $>\mathrm{E}$ and $\mathrm{F}>\mathrm{D}>\mathrm{A}>\mathrm{B}>\mathrm{C}$.

Regarding the additional surface of heat and mass transfer, the drift eliminator area per unit of volume, also called packing density, the sequence would be: drift eliminators $\mathrm{F}$ and $\mathrm{E}$ are those with higher packing density values, followed by drift eliminator $\mathrm{D}$, then drift eliminators made of laths, from the largest number to the smallest number of laths, (C, B and A). In last place is the case without an eliminator since it does not add additional surface.

Then, eliminators sorted by the additional surface of heat and mass transfer are: E and F $>$ D $>$ C $>$ B $>$ A> No Eliminator.

The relative importance of both physical phenomena described above lead to different cooling tower thermal performance. Figure 6 shows the cooling tower has its best performance with the eliminators $\mathrm{E}$ and $\mathrm{F}$ in the full range of water-to-air mass flow ratio. This is justified by the great packing density and the less altered flow pattern introduced.

Looking at the eliminators formed by laths, for low values of water-to-air mass flow ratio, the sequence is $(B>A>C)$ and for high values of water-to-air mass flow ratio, the sequence is $(B>C>A)$. This shows that the drift eliminator $\mathrm{B}$ is the eliminator formed by laths that offers the best compromise between packing density and asymmetry in the flow. When the values of water-to-air mass flow ratio are low, i.e. in situations with low water mass flow, it is expected to lower the drift and thus the dominant effect is the less altered flow pattern introduced and that is why the eliminator A enhancement to C. In the case of a high water-to-air mass flow ratio where higher levels of entrained water is expected, the greater packing density of eliminator $\mathrm{C}$ causes better thermal performance of the tower than eliminator $\mathrm{A}$.

Noting eliminator D, there is a change of position on the eliminators formed by laths. For low levels of water-to-air mass flow ratio, eliminator $\mathrm{D}$ has better performance than those with laths, such as is expected according to the two criteria described previously. However, for high levels of water-to-air mass flow ratio, eliminator D has worse behavior than the form of laths unlike what was expected. This can only be justified for even having greater packing density, its geometry and how it gets wet; it can finally offer a minor additional wet surface. 
In response to the middle position of the experiment without the drift eliminator, this is checked as the presence of an eliminator does not necessarily worsen the performance of a cooling tower as expected by the additional pressure loss incorporated into the airflow. In this case, the absence of the eliminator increases the $h_{D}$ while it does not add extra packing. 


\section{Correlation and validation}

The cooling TC corresponding to different operating conditions can be correlated in terms of the water-toair mass flow ratio, or water mass flow and air mass flow separately, as suggested by ASHRAE [22].

$$
\begin{aligned}
& T C=\frac{h_{D} \cdot A_{v} \cdot V}{m_{w}}=C \cdot\left(\frac{m_{w}}{m_{a}}\right)^{-n} \\
& T C=\frac{h_{D} \cdot A_{V} \cdot V}{m_{w}}=C \cdot m_{w}^{-n} \cdot m_{a}^{m}
\end{aligned}
$$

The correlation presented in equation (9) has been defined as the water-to-air mass flow ratio correlation (L/G correlation) whilst the other is referred in this text to the water and air mass flow ratios correlation ( $L$ and $\mathrm{G}$ correlation). In order to evaluate which correlation yielded better results and to validate the experimental values obtained in the tests, a comparison between the correlations was carried out. The results of these comparisons between calculated and measured outlet water temperatures, displayed in Table 4, show for the water-to-air mass flow ratio correlation a maximum averaged deviation of $1.61 \%$ from the measured values, while for the water and air mass flow ratios, the correlation maximum averaged differences of $0.95 \%$ between the calculated and predicted temperatures was observed. Constants c, $\mathrm{n}$ and $\mathrm{m}$ for ASHRAE's correlations of the TC in terms of the water-to-air mass flow ratio in the first place and mass flows separately in the second, obtained for the tested drift eliminators and the gravity water distribution system, are presented in Table 5 and Table 6, respectively.

In light of this, it can be concluded that ASHRAE's correlations predict the thermal performance of the cooling tower well because the predicted results are remarkably confident (less than $2 \%$ difference in both correlations). Nevertheless, the best results are obtained by using the L and G correlation where mass flow ratios are the independent variables instead of the water-to-air mass flow ratio. The calculated and experimental outlet water temperatures are represented in Figure 8. 


\section{Conclusions}

This study has enabled investigating the effect of the water distribution system on the thermal performance of a forced draft counter-flow cooling tower (FDCT) filled with six different types of drift eliminators. The results obtained during the investigation within a range of experimental conditions of air and water mass flows can be summarized as follows.

It has been assessed by the experimental calculation of the TC that the physical configuration of the water spread by the water distribution system influences the thermal performance of the cooling tower for the same water-to-air mass flow ratio. Comparing PWDS and GWDS results, it can be observed that for each drift eliminator tested, the cooling tower capacity is higher when PWDS is equipped. The explanation given to this phenomenon is related to the small droplet size achieved with the PWDS because of the breaking up of the water into small particles. As the size of the droplets obtained by PWDS is smaller, the heat and mass exchange area per unit of volume increases.

Two factors have been found to be the reason for the cooling difference between eliminators. On the one hand, the wetting of the eliminators because the cooling tower drift leads to the drift eliminator contributing to the heat and mass transfer exchange because of the increase in the $A_{V}$ term. On the other hand, the variation of the convective mass transfer coefficient $h_{D}$ will affect the tower characteristic depending on the flow pattern enforced by the eliminator. The second effect will be dominant when the cooling tower drift is negligible, which occurs when the GWDS is equipped. The presence of an eliminator does not necessarily worsen the performance of a cooling tower as expected by the additional pressure loss incorporated into the airflow. In this case, the absence of the eliminator increases the $h_{D}$ while it does not add extra packing.

It can be concluded that the proposed correlations predict the thermal performance of the cooling tower well because the predicted results are remarkably confident (less than a $3 \%$ difference in both correlations). The usefulness of having correlations for the TC is that the energy consumption of the thermal system might be evaluated for different water distribution systems and drift eliminators in order to find the pair of these elements that minimize energy consumption, keeping constant the level of cooling tower drift. As the tests of cooling tower drift for the water distribution systems are still in process, there is not an available criterion for selecting a drift eliminator-water distribution system in order to optimize both the collection efficiency and the cooling tower's thermal performance. This criterion would be the result of future research. 


\section{Acknowledges}

The authors wish to acknowledge the collaboration of the Ministerio de Educación y Ciencia (Spanish Education and Science Ministry) for their support of project PN I+D+I 2008-2011 ENE2010-21679-C0202. 


\section{References}

[1] B.G. Lewis, On the question of airborne transmission of pathogenic organisms in cooling tower drift, 1974, Cooling Tower Institute, Technical Paper-T-124A.

[2] G.C. Pedersen, V.K. Lamkin, M. Seich, An economical solution to cooling tower drift, Cooling Tower Institute, 1897, Technical Paper- T-87-08.

[3] R.H. Bentham, C.R. Broadbent, A model autumn outbreaks of Legionnaries’ disease associate with cooling towers, linked to system operation and size, Epidemiol Infect 111, 1993, 287-295.

[4] R. Isozumi, Y. Ito, I. Ito, M. Osawa, T. Hirai, S. Takakura, et al, An outbreak of Legionella pneumonia originating from a cooling tower, Scand. J. Infect. Dis., 2005, 37(10) 709-11.

[5] J. Chan, M.W. Golay, Comparative evaluation of cooling tower drift eliminator performance, Energy Laboratory Report MIT-El 77-004, 1977.

[6] A.K.M. Mohiuddin, K. Kant, Knowledge base for the systematic design of wet cooling towers, part I: selection and tower characteristics, Int. J. Refrigeration, 1996, 19 (1) 43-51.

[7] B. Zamora, A.S. Kaiser, Comparative efficiency evaluations of four types of cooling tower drift eliminator, by numerical investigation, Chemical Engineering Science, in press.

[8] W.J. Thomas, P. Houston, Simultaneous heat and mass transfer in cooling towers. Brit. Chem. Eng, 1959, 160-217.

[9] H.J. Lowe, D.G. Christie, Heat transfer and pressure drop data on cooling tower packings, and model studies of the resistance of natural draft towers to air flow, Inst Mech Eng (Steam Group) Symposium on Heat Transfer, 1962, 113-933.

[10] N.W. Kelly, L.K. Swenson, Comparative performance of cooling tower packing arrangements, Chemical Engineering Progress, 1956, 52, 263-268.

[11] H.R. Goshayshi, J.F. Missenden, The investigation of cooling tower packing in various arrangements, Applied Thermal Engineering, 2000, 20, 69-80.

[12] S.V. Bedekar, P. Nithiarasu, K.N. Seethatamu, Experimental investigation of the performance of a counter flow packed bed mechanical cooling tower, Energy, 1998, 23, 943-947.

[13] N. Milosavljevic, P.A. Heikkila, Comprehensive approach to cooling tower design, Applied Thermal Engineering, 2001, 21, 899-915.

[14] F. Gharagheizi, R. Hayati, S. Fatemi, Experimental study on the performance of mechanical cooling tower with two types of film packing, Energy Conversion and Management, 2007, 48, 277-280. 
[15] M. Lemouari, M. Boumaza, I.M. Mujtaba, Thermal performances investigation of a wet cooling tower, Applied Thermal Engineering, 2007, 27, 902-909.

[16] E. Elsarrag, Experimental study and predictions of an induced draft ceramic tile packing cooling tower, Energy Conversion and Management, 2006, 47, 2034-2043.

[17] E. Hajidavalloo, R. Shakeri, M. A. Mehrabian, Thermal performance of cross flow cooling towers in variable wet bulb temperature, Energy Conversion and Management, 2010, 51, 1298-1303.

[18] M. Lucas, P.J. Martínez, A. Viedma, Experimental study on the thermal performance of a mechanical cooling tower with different drift eliminators, Energy Conversion and Management, 2009, 50 490-497.

[19] F. Merkel, Evaporative Cooling, Zeits, Verein Deutscher Ingenieure, 1926, 70, 120-128.

[20] CTI Code Tower, Standard Specifications. Acceptance Test Code for Water Cooling Towers, Cooling Technology Institute, 2000.

[21] ISO Guide, Guide to the expression of uncertainty in measurement, 1993, ISBN: 92-67-10188-9.

[22] ASHRAE Handbook CD—HVAC Systems and Equipment, 2004, Chapter 36. 
Tables

\begin{tabular}{cccc}
\hline Water temperature $\left(\mathrm{t}_{\mathrm{w}}\right)$ & $\begin{array}{c}\text { Enthalpy of saturated air at } \\
\text { water temperature }\left(\mathrm{h}_{\mathrm{s}, \mathrm{w}}\right)\end{array}$ & Enthalpy of air $(\mathrm{h})$ & $\mathrm{1}\left(\mathrm{h}_{\mathrm{s}, \mathrm{w}}-\mathrm{h}\right)_{\mathrm{j}}$ \\
\hline $\mathrm{t}_{\mathrm{w}, 2}$ & $\mathrm{~h}_{\mathrm{s}, \mathrm{w}}\left(\mathrm{t}_{\mathrm{A}}\right)$ & $\mathrm{h}_{1}$ & \\
$\mathrm{t}_{\mathrm{A}}=\mathrm{t}_{\mathrm{w}, 2}+0.1\left(\mathrm{t}_{\mathrm{w}, 1}-\mathrm{t}_{\mathrm{w}, 2}\right)$ & $\mathrm{h}_{\mathrm{s}, \mathrm{w}}\left(\mathrm{t}_{\mathrm{B}}\right)$ & $\mathrm{h}_{\mathrm{B}}=\mathrm{h}_{1}+0.1\left(\mathrm{~h}_{2}-\mathrm{h}_{1}\right)$ & $1 /\left(\mathrm{h}_{\mathrm{s}, \mathrm{w}}\left(\mathrm{t}_{\mathrm{A}}\right)-\mathrm{h}_{\mathrm{A}}\right)$ \\
$\mathrm{t}_{\mathrm{B}}=\mathrm{t}_{\mathrm{w}, 2}+0.4\left(\mathrm{t}_{\mathrm{w}, 1}-\mathrm{t}_{\mathrm{w}, 2}\right)$ & $\mathrm{h}_{\mathrm{s}, \mathrm{w}}\left(\mathrm{t}_{\mathrm{C}}\right)$ & $1 /\left(\mathrm{h}_{\mathrm{s}, \mathrm{w}}\left(\mathrm{t}_{\mathrm{B}}\right)-\mathrm{h}_{\mathrm{B}}\right)$ \\
$\mathrm{t}_{\mathrm{C}}=\mathrm{t}_{\mathrm{w}, 2}+0.6\left(\mathrm{t}_{\mathrm{w}, 1}-\mathrm{t}_{\mathrm{w}, 2}\right)$ & $\mathrm{h}_{\mathrm{C}}=\mathrm{h}_{1}+0.6\left(\mathrm{~h}_{2}-\mathrm{h}_{1}\right)$ & $1 /\left(\mathrm{h}_{\mathrm{s}, \mathrm{w}}\left(\mathrm{t}_{\mathrm{C}}\right)-\mathrm{h}_{\mathrm{C}}\right)$ \\
$\mathrm{t}_{\mathrm{D}}=\mathrm{t}_{\mathrm{w}, 2}+0.9\left(\mathrm{t}_{\mathrm{w}, 1}-\mathrm{t}_{\mathrm{w}, 2}\right)$ & $\mathrm{h}_{\mathrm{D}}=\mathrm{h}_{1}+0.9\left(\mathrm{~h}_{\mathrm{D}}-\mathrm{h}_{1}\right)$ & $1 /\left(\mathrm{h}_{\mathrm{s}, \mathrm{w}}\left(\mathrm{t}_{\mathrm{D}}\right)-\mathrm{h}_{\mathrm{D}}\right)$ \\
$\mathrm{t}_{\mathrm{w}, 1}$ & & $\mathrm{~h}_{2}$ & \\
\hline
\end{tabular}

Table 1: Calculation procedure for the TC.

\begin{tabular}{cccc}
\hline Parameter & Sensor & Range & Accuracy \\
\hline Water temperature & Pt 100 type RTD & $-200^{\circ} \mathrm{C}-600^{\circ} \mathrm{C}$ & $0.08^{\circ} \mathrm{C}$ \\
Water flow rate & Oval wheel flow meter & $2-20 \mathrm{~m}^{3} \mathrm{~h}$ & $0.4 \%$ f.s. \\
Outlet air velocity & Vane anemometer & $0.5-20 \mathrm{~m} / \mathrm{s}$ & $0.1 \mathrm{~m} / \mathrm{s} \pm 1.5 \% \mathrm{~m} . \mathrm{v}$. \\
Outlet air temperature & Capacitive & $-20^{\circ} \mathrm{C}-80^{\circ} \mathrm{C}$ & $0.3^{\circ} \mathrm{C}$ \\
Outlet air relative humidity & Capacitive & $0-100 \%$ & $\pm 2 \%$ \\
Ambient temperature & Pt 1000 type RTD & $-50^{\circ} \mathrm{C}-50^{\circ} \mathrm{C}$ & $0.2^{\circ} \mathrm{C}$ \\
Ambient relative humidity & Capacitive & $0-100 \%$ & $3 \%(10-90 \%) / 4 \%(0-$ \\
Wind velocity & Cup anemometer & $0-50 \mathrm{~m} / \mathrm{s}$ & $10 \%, 90-100 \%)$ \\
Atmospheric pressure & Solid State & $794-1050 \mathrm{mbar}$ & $0.3 \mathrm{~m} / \mathrm{s}$ \\
\hline
\end{tabular}

Table 2: Measuring devices specifications.

\begin{tabular}{ccc}
\hline \multirow{2}{*}{ Drift eliminator } & Max difference (\%) & $\begin{array}{c}\text { Averaged difference } \\
(\%)\end{array}$ \\
\hline A & 53.25 & 38.66 \\
B & 5.47 & 5.37 \\
C & 19.44 & 18.35 \\
D & 28.80 & 18.30 \\
E & 22.69 & 18.34 \\
F & 19.45 & 16.51 \\
NONE & 34.78 & 32.90 \\
\hline
\end{tabular}

Table 3: Averaged and maximum difference in terms of correlated TC between distribution systems for every eliminator. 


\begin{tabular}{ccc}
\hline Type of drift eliminator & L/G correlation & L and G correlation \\
\hline A & 1.59 & 0.64 \\
B & 1.12 & 0.62 \\
C & 1.32 & 0.60 \\
D & 1.22 & 0.75 \\
E & 1.61 & 0.95 \\
F & 1.11 & 0.51 \\
NONE & 1.04 & 0.63
\end{tabular}

Table 4: Averaged differences in \% in terms of outlet water temperature for the eliminators tested between correlations.

\begin{tabular}{ccc}
\hline Type of drift eliminator & c & $\mathrm{n}$ \\
\hline A & 0.518 & 0.573 \\
B & 0.593 & 0.549 \\
C & 0.522 & 0.463 \\
D & 0.586 & 0.733 \\
E & 0.669 & 0.6 \\
F & 0.670 & 0.525 \\
NONE & 0.557 & 0.516
\end{tabular}

Table 5: Calculated correlated parameters of characteristic ratio for the eliminators tested for the water-to-air mass flow ratio correlation.

\begin{tabular}{cccc}
\hline Type of drift eliminator & c & $\mathrm{n}$ & $\mathrm{m}$ \\
\hline A & 0.522 & 0.373 & 0.768 \\
B & 0.612 & 0.370 & 0.739 \\
C & 0.529 & 0.144 & 0.733 \\
D & 0.601 & 0.507 & 0.960 \\
E & 0.751 & 0.447 & 0.787 \\
F & 0.726 & 0.316 & 0.686 \\
NONE & 0.565 & 0.322 & 0.766
\end{tabular}

Table 6: Calculated correlated parameters of characteristic ratio for the eliminators tested for the L and G correlation. 


\section{Figure captions}

Figure 1: Heat and mass transfer at the water-air interface.

Figure 2: Schematic diagram of FDCT.

Figure 3: From left to right and up to down: water distribution systems tested; GWSD and PWSD.

Schematic arrangement of the water distribution systems tested; GWSD and PWSD.

Figure 4: Drift eliminators tested. From left to right and up to down: Drift eliminator A, drift eliminator D, drift eliminator B, drift eliminator E, drift eliminator C and drift eliminator F.

Figure 5: Cooling tower characteristic versus water-to-air mass flow ratio for the six eliminators tested and no drift eliminator for the GWDS.

Figure 6: Cooling tower characteristic versus water-to-air mass flow ratio for the correlations of the six eliminators tested and no drift eliminator for the GWDS.

Figure 7: Cooling tower characteristic versus water-to-air mass flow ratio for the correlations of the six eliminators tested and no drift eliminator. Comparison between GWDS and PWDS.

Figure 8: Relation between experimental and predicted cooling tower outlet water temperature. 
Figure 1: Heat and mass transfer at the water-air interface.

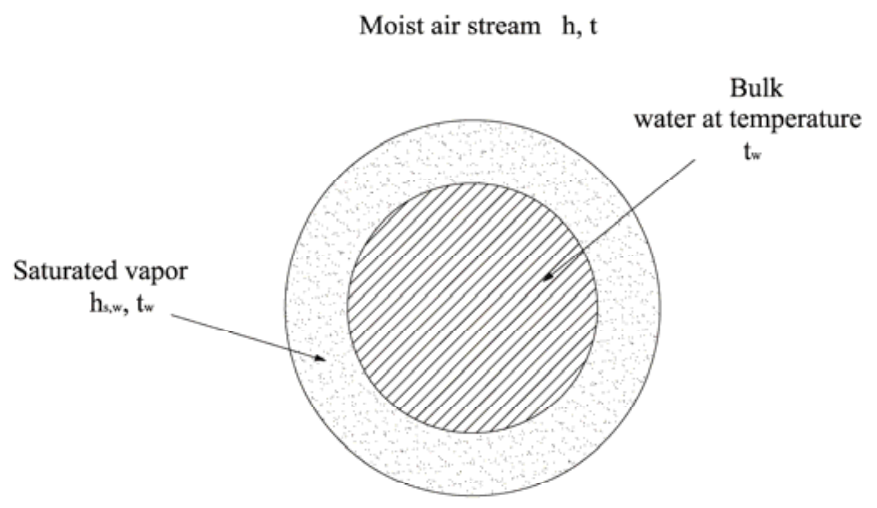


Figure 2: Schematic diagram of FDCT.

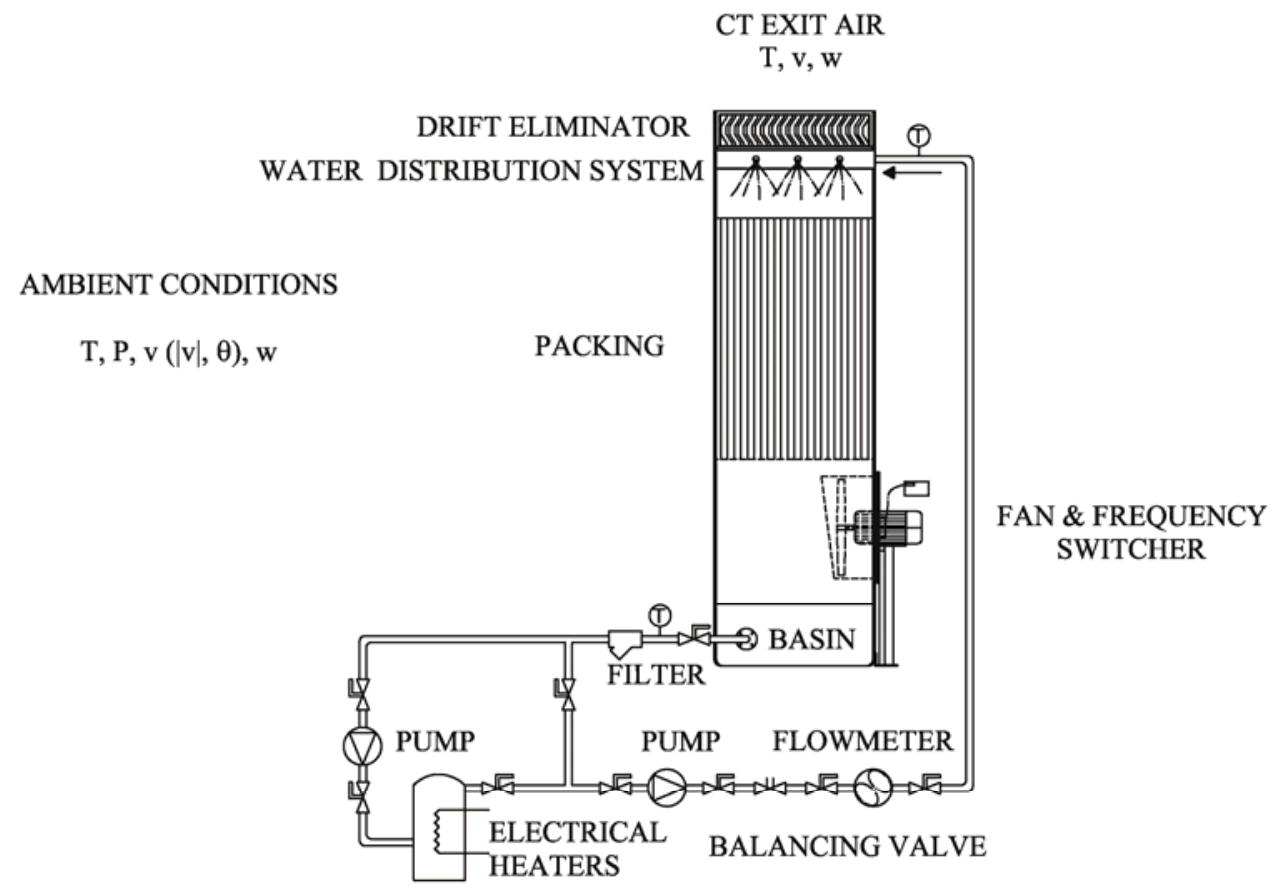


Figure 3: From left to right and up to down: water distribution systems tested; GWSD and PWSD. Schematic arrangement of the water distribution systems tested; GWSD and PWSD.
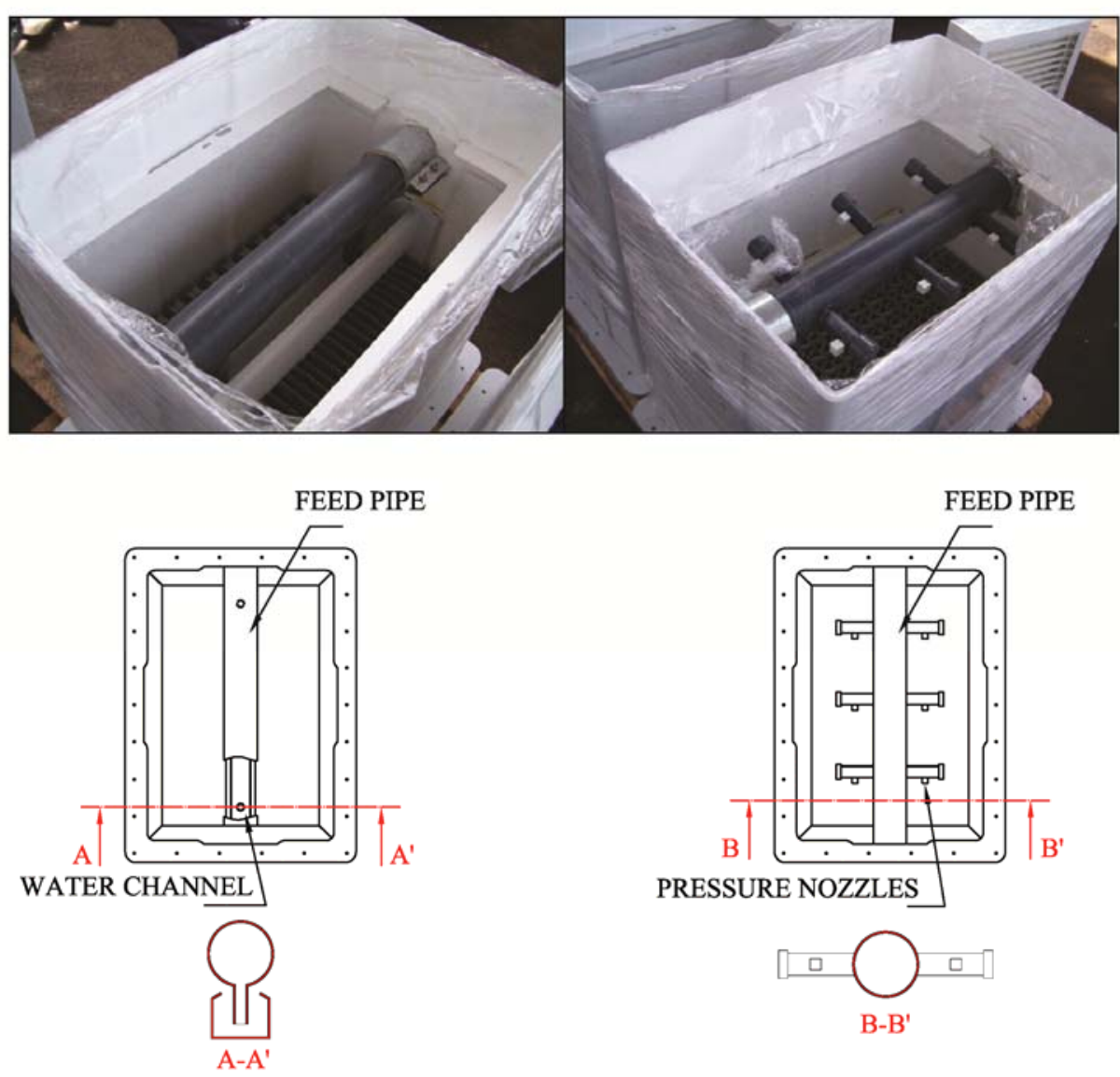
Figure 4 Drift eliminators tested. From left to right and up to down: Drift eliminator A, drift eliminator D, drift eliminator B, drift eliminator E, drift eliminator C and drift eliminator F.

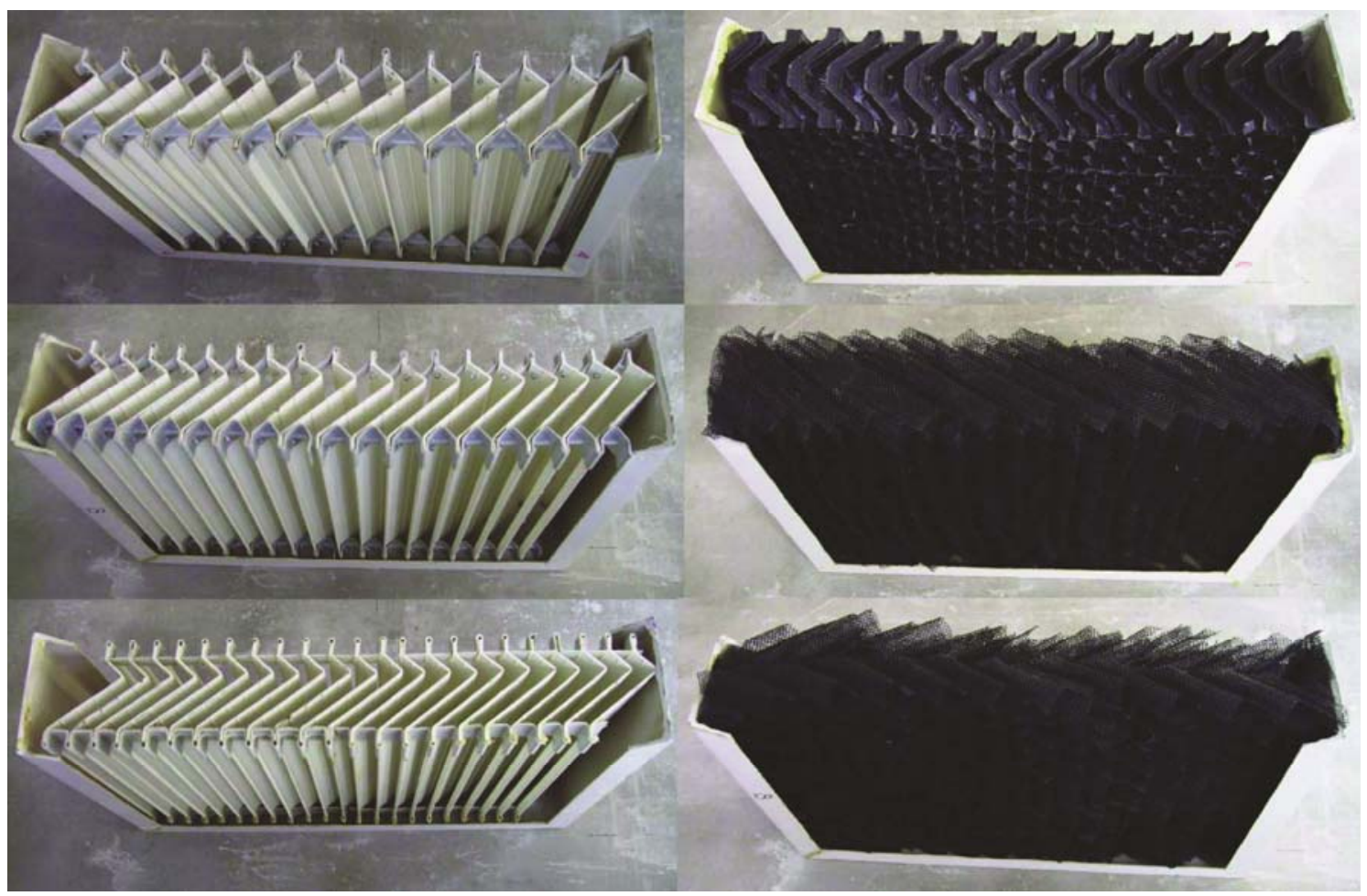


Figure 5: Cooling tower characteristic versus water-to-air mass flow ratio for the six eliminators tested and no drift eliminator for the GWDS.

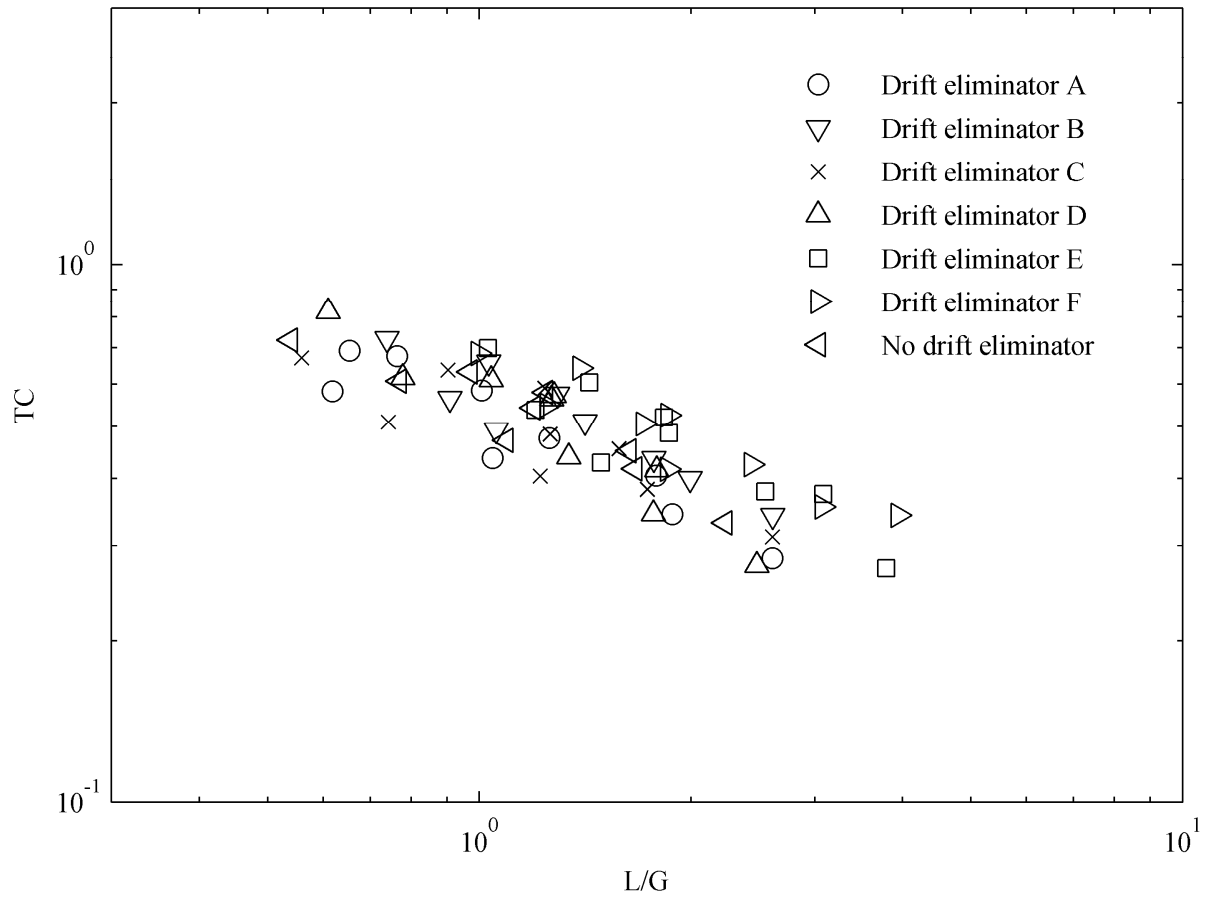


Figure 6: Cooling tower characteristic versus water-to-air mass flow ratio for the correlations of the six eliminators tested and no drift eliminator for the GWDS.

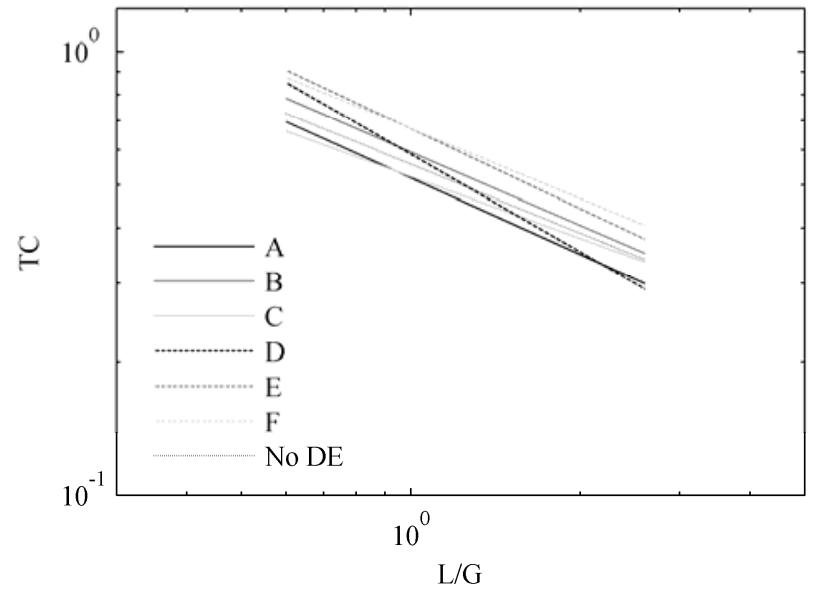


Figure 7: Cooling tower characteristic versus water-to-air mass flow ratio for the correlations of the six eliminators tested and no drift eliminator. Comparison between GWDS and PWDS.
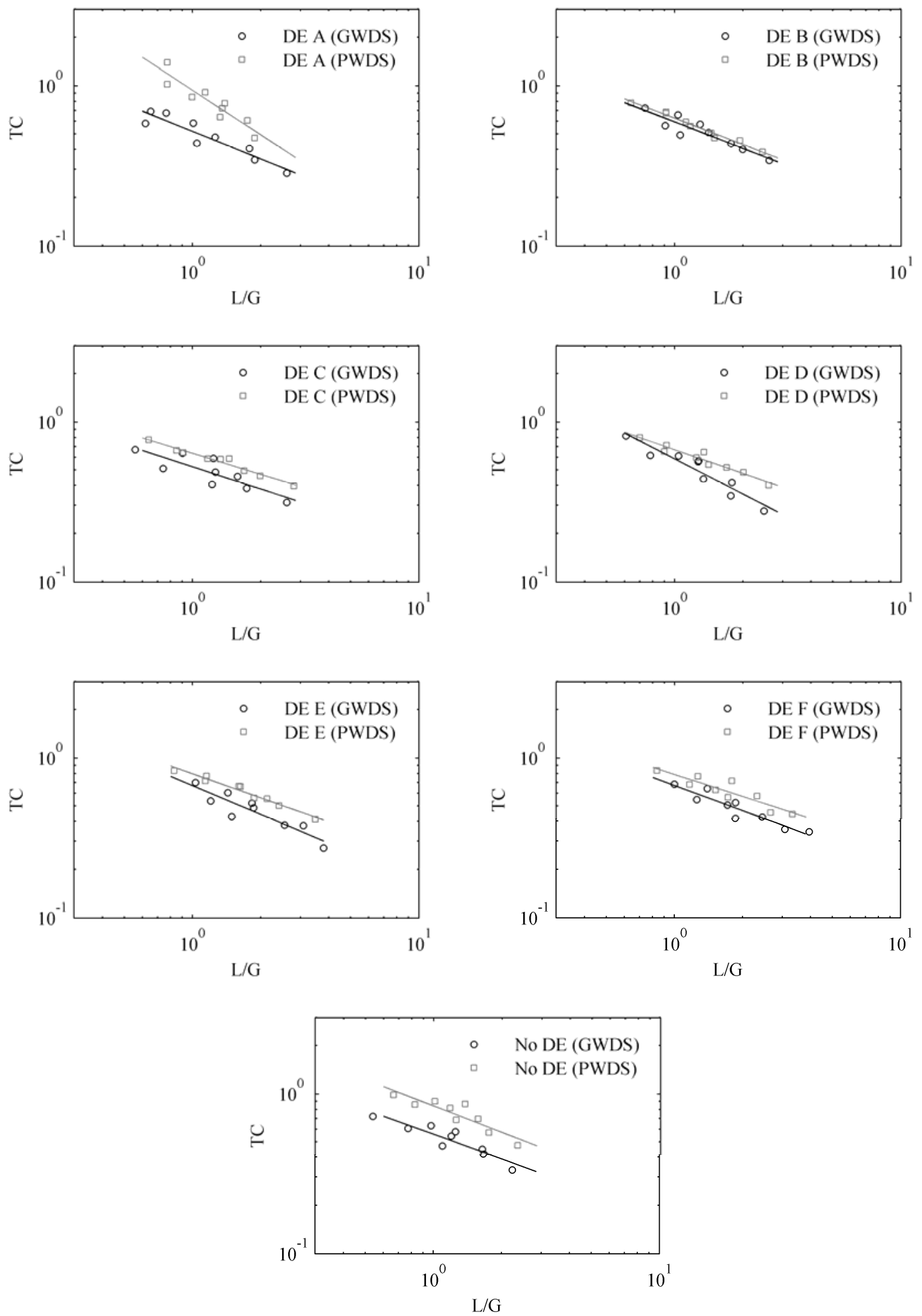
Figure 8: Relation between experimental and predicted cooling tower outlet water temperature.
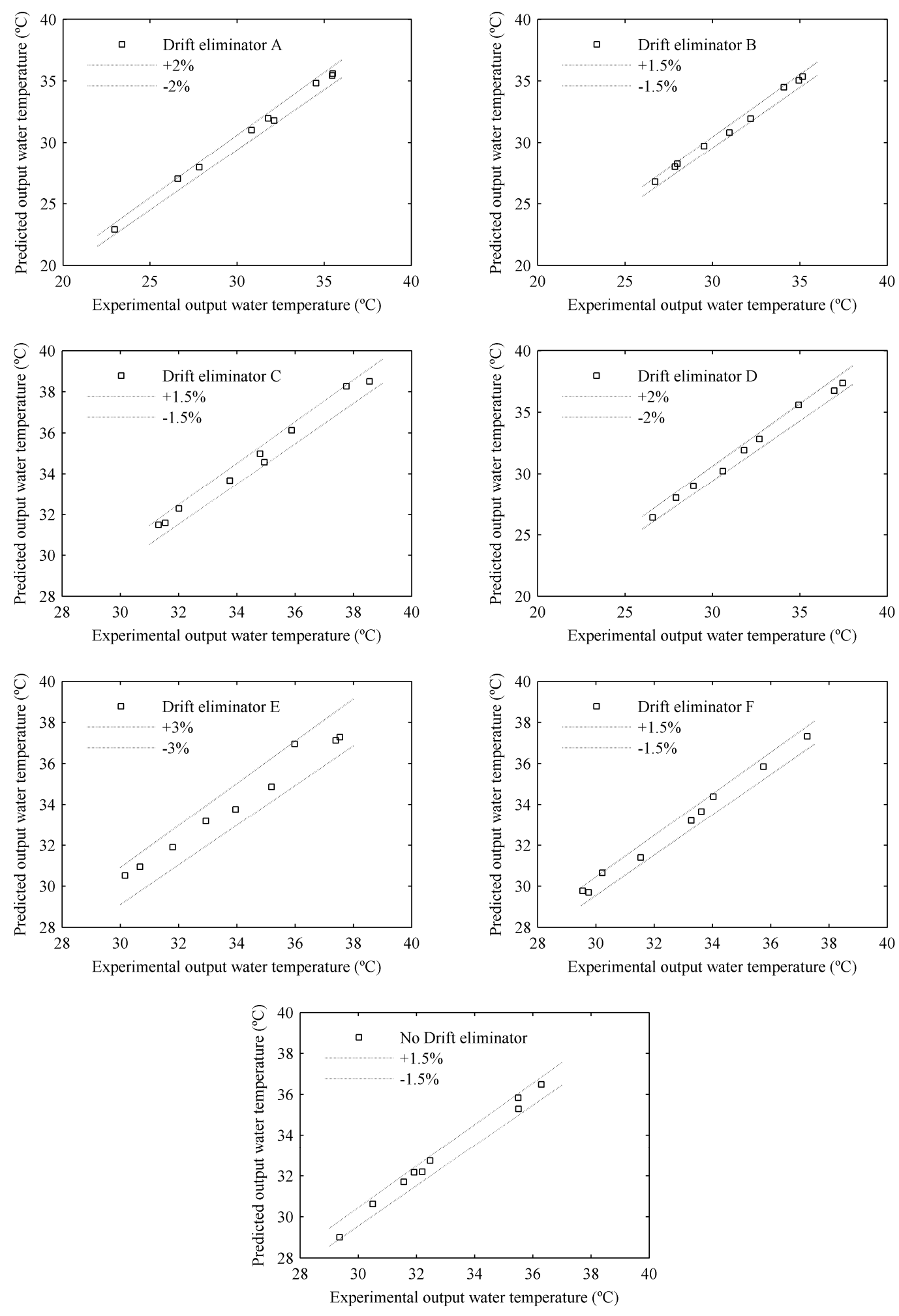